\title{
Self-Regulation of Emotion Module to Reduce Aggressive Behavior
}

\author{
Said Alhadi, Wahyu Nanda Eka Saputra, Purwadi, Amien Wahyudi, Agus Supriyanto, Siti Muyana \\ Department of Guidance and Counseling \\ Universitas Ahmad Dahlan \\ Yogyakarta, Indonesia \\ said.alhadi@bk.uad.ac.id
}

\begin{abstract}
The present study aimed at identifying the level of aggressive behavior in students, formulating hypothetical drafts of products, and develop self-regulation of emotion module for reducing students' aggressive behavior. This study adapted the research and development of Gall, Borg \& Gall, which in the development procedure was limited to three stages, namely (1) identification of students' aggressive behavior; (2) the formulation of hypothetical draft of self- regulation of emotion module; and (3) Product feasibility test which was carried out by expert and practitioner. The data were analyzed using quantitative descriptive analysis. The study was conducted in Junior high schools in the Special Region of Yogyakarta. The result of the study showed that the self-regulation of emotion module was developed by including the components of selfregulation of emotion, namely receiving, evaluating, triggering, searching, formulating, implementing, and assessing. Besides, the self-regulation of emotion module is categorized as feasible to be implemented by the counselor to support the counselor's program in reducing students' aggressive behavior.
\end{abstract}

Keywords-self-regulation of emotion module; aggressive behavior

\section{INTRODUCTION}

This study was conducted due to the emergence of various problems related to students' aggressive behavior. One of the studies on Junior High School students in Yogyakarta Indonesia concluded that $1 \%$ of them was categorized as very high, $13 \%$ of them was categorized as high, $37 \%$ of them was categorized as medium, $43 \%$ of them was categorized as low, and $6 \%$ of them was categorized as very low [1]. Another study on Vocational High School students in Yogyakarta also found that there were $5 \%$ of the students whose aggressive behavior was categorized as very high, $26 \%$ of them was categorized as high, $40 \%$ of them was categorized as medium, $21 \%$ of them was categorized as low, and $8 \%$ of them was categorized as very low [2]. Even, there is a study in Yogyakarta showing that there is no significant difference between male and female Vocational High School students in Yogyakarta regarding aggressive behavior [3].

In another city, A study was conducted in Padang, West Sumatra Indonesia, the study revealed that $35.32 \%$ of the students' aggressive behavior was by physical violence, $41.30 \%$ of them were by verbal violence, and $30.42 \%$ of them was by vandalism [4]. It is frustrating to see adolescents behave aggressively since they tend to do physical violence, verbal violence, and vandalism. Another data showed that among 1169 adolescents aged $15-16$ years old, $70 \%$ of them were the victim and the actor of aggressive behavior [5]. The next study showed that $69.5 \%$ of physical aggressiveness done by children in the urban area was in the form of slapping, punching, raping, and other risky behavior [6].

Students' aggressive behavior does not emerge without warning; some factors result in it. One of the factors leading to aggressive behavior is anger. Many studies have concluded that aggressive behavior is related to someone's anger [7]-[9]. According to the studies, it is understandable that an individual with high anger tends to lead to aggressive behavior.

In addition to anger, emotion also results in aggressive behavior. Someone's ability to regulating emotion becomes one of the factors resulting in aggressive behavior. A study concluded that someone's ability $\mathrm{n}$ contributes to their aggressive behavior [10]. That study found that someone who finds it difficult to regulate their emotions tends to consume alcohol and commit sexual aggressiveness. An emotional quotient also contributes to someone's aggressive behavior. Many studies conclude that emotional quotient significantly affects students' aggressive behavior [11], [12].

Based on some studies, it could be concluded that students' failure in regulating their emotions is one of the vital aspects leading to the emergence of students' aggressive behavior. Some forms of aggressive behavior in Junior High School students in the Special Region of Yogyakarta are ridiculing, saying rude on social media, hurting physically, and throwing out anger on others. Someone's ability to regulating emotion is usually known as the self-regulation of emotion [13], [14]. Based on the result of the study, self-regulation of emotion may trigger an individual to transform their negative emotion [13]. Someone's response to the stimulus is determined by intertwined affective, cognitive, and arousal aspects [15]. In other words, an individual's internal condition will regulate the emergence of aggressive behavior.

Buttler and Gross stated that uncontrolled self-regulation of emotion might hamper interpersonal relationship, for instance, it may lead to the uncontrollable expression of anger, enhancing aggressive behavior [16]-[18]. An individual who fails to utilize his/her self-regulation ability may increase the risk of aggressive behavior [19], [20]. Self-regulation of emotion is an important aspect of establishing the interpersonal relationship. To maximize the self-regulation of emotion, an 
adolescent needs proper guidance, direction, and services. To this end, the counselor may take active participation in providing services that could maximize adolescent's ability to self-regulation of emotion.

By paying attention to the need and students' selfregulation of emotion, creativity and innovation of the counselor are required to creating new strategies that can be used to develop self-regulation of emotion. The need to develop self-regulation of emotion is seen from many and varied aggression behaviors carried out by students, especially in junior high school students in the Special Region of Yogyakarta. To assist students in improving their selfregulation of emotion, one of the media that can be used efficiently is a module. Accordingly, a question posed by the present study is whether or not the self-regulation of emotion module feasible to be applied in assisting students to reduce their aggressive behavior. If it is found that the module is feasible, the school counselors can utilize it for reducing students' aggressive behavior. Opportunities in further research to measure the effectiveness of the self-regulation of emotion module to reduce students' aggressive behavior.

\section{METHOD}

The present study was categorized as Research and Development $(\mathrm{RnD})$. This study was aimed at identifying students' aggressive behavior which was considered as the basis of the development of the module. This study was conducted under the pattern proposed by Borg and Gall which is limited by three stages of development namely (1) problem identification; (2) the formulation of draft of hypothetical product; and (3) expert and practitioner's judgment to see the product feasibility based on three aspects, namely product overview, the function of the product, and product accuracy. [21]. For future study, there is an opportunity to continue this study by identifying the effectiveness of the self-regulation of emotion in reducing aggressive behavior.

There were two types of instruments in the study. The first instruments of the scale adopts an aggressive behavior scale whose validity and reliability have been tested [22]. The second instrument was the assessment sheet filled by the expert and practitioner (school counselor) to assess the feasibility of the product (self-regulation of emotion module for reducing aggressive behavior). The assessment sheet consists of three aspects, product overview, the function of the product, and product accuracy.

Needs assessment identification was made by distributing instruments (aggressive behavior scale) to the Junior High School students in the Special Region of Yogyakarta. The population of the study was 293.568 students. The present study employed a cluster random sampling technique, the total sample of the study was 945 students. To judge the feasibility of the product, the judgment was done by an expert (a lecturer in the guidance and counseling program of Semarang State University with expertise in the field of guidance and counseling innovation). Besides, the assessment was also done by the practitioner namely the school counselor who is an expert in providing counseling services to promote counselee's behavioral change.
The data of the study were analyzed using quantitative data analysis. This was done by describing the students' level of aggressive behavior. Accordingly, the percentage of students' aggressive behavior would be found in the category of 'very high', 'high', 'intermediate', 'low', 'very low'. Besides, Cohen's Kappa coefficient of inter-rater reliability (IRR) analysis described the level of feasibility of the product.

\section{RESULTS AND DISCUSSION}

This study was started by conducting a study on students' problems related to aggressive behaviors they did. The result of the study showed that $1 \%$ of the student's aggressive behavior was categorized as very high, $13 \%$ was categorized as high, $37 \%$ of them was categorized as a medium, $43 \%$ of them was categorized as low, and $6 \%$ of them was categorized as very low. The first finding of the study become one of the reasons to develop the self-regulation of emotion module.

This module consists of eleven parts. Those are: (a) Introduction; (b) understanding aggressive behavior; (c) the concept of self-regulation of emotion; (d) learning the concept of receiving; (e) learning the concept of evaluating; (f) learning the concept of triggering; $(\mathrm{g})$ learning the concept of searching; (h) learning the concept of formulating; (i) learning the concept of implementing; (j) learning the concept of assessing; and (k) closing. These parts refer to the theoretical concept of Miller and Brown, the development of self-regulation of emotion theory that is used to assist students in regulating their emotions [23] so that their aggressive behavior reduces.

The feasibility of the product was determined by the expert and practitioner's judgment. The following table shows the product feasibility by the expert and practitioner.

TABLE I. RESULTS OF EXPERT'S AND PRACTITIONER'S JUDGEMENT

\begin{tabular}{clc}
\hline No & \multicolumn{1}{c}{ Aspect } & Average Score \\
\hline 1 & $\begin{array}{l}\text { Product overview } \\
2\end{array}$ & $\begin{array}{l}\text { Product accuracy in reducing aggressive } \\
\text { behavior }\end{array}$ \\
3 & $\begin{array}{l}\text { Product usability for counselor in reducing } \\
\text { students' aggressive behavior }\end{array}$ & 3,27 \\
\multicolumn{2}{c}{ Average } & 3,1 \\
\hline
\end{tabular}

This judgment was done specifically by one expert (a lecturer and researcher in the Guidance and Counseling Department) and one practitioner (School counselor in Junior High School). The average score of expert's and practitioner's judgment was 3.18. To identify the product feasibility, Cohen's Kappa Coefficient of inter-rater reliability (IRR) analysis was used toward the agreement between two raters. Based on the result of the analysis the following result was obtained.

Cohen's Kappa Coefficient Inter-rater reliability analysis showed that inter-rater reliability was $\mathrm{K}=0.612$ and categorized as strong. The value of Cohen's kappa coefficient means that there is a strong agreement between the expert and the practitioner regarding the product developed by this study.

Its significance was 0.000 . Since the significance was smaller than $5 \%$ of the level of significance $(0.000<0.05)$, it could be concluded that there is a significant agreement 
between expert and the practitioner in the level of 5\% significance related to the product being developed.

The main finding of the study is that the self-regulation of emotion module is categorized as feasible to be implemented by the school counselors for reducing students' aggressive behavior. However, the effectiveness of the products produced has not been measured empirically. Emotion becomes one of the targets the students need to manage to reduce the tendency of aggressive behavior. Some studies also conclude that selfregulation of emotion affects aggressive behavior [24]-[26]. Someone's failure in the self-regulation of emotion may result in the emergence of aggressive behavior [27], [28].

Within the self-regulation of emotion module, the students are trained to learn to control their emotions. Self-control on emotion becomes a pivotal aspect of reducing aggressive behavior. Studies conclude that an individual's self-control can encourage he/she reducing aggressive behavior [20], [29]. The better someone in controlling themselves, the lower their level of aggressive behavior. The worse someone in controlling themselves, the higher their level of aggressive behavior.

The self-regulation of emotion module also emphasizes the students' ability in regulating their explosive anger. The students are encouraged to learn regulating anger which often results in aggressive behavior that harms both themselves and other people. Some studies showed that an individual's anger regulation would affect their level of aggressive behavior [7], [8], [30]-[32]. The role of cognitive control is significant in controlling an individual's anger so that his/her aggressive behavior decreases [33].

The current study is also supported by some previous studies that emphasize the importance of self-regulation of emotion. One of the studies concludes that aggression control therapy can be used to reduce violent forensic psychiatric patients [34]. However, the study was implemented in a clinical condition with forensic psychiatric patients as the subject. It is different from the current study which the implementation is in the educational field by specifically emphasizing the use of self-regulation of emotion module for reducing students' aggressive behavior.

Another study also concludes that anger management leadership groups become one of the creative techniques for reducing students' aggressive behavior [35]. That study was conducted in school, however, the study focused on the use of anger management that is implemented in a group setting. Meanwhile, the present study emphasized the use of the module to facilitate the students regulating their emotions.

Another study showed that The GREAT Teacher Program (Guiding Responsibility and Expectations for Adolescents for Today and Tomorrow) is one of the teacher's programs that can be used to help to prevent and reduce students' aggressive behavior [36]. The study was conducted in the school setting. However, its implementation was done by teachers and was not specific on students' regulation of emotion. While in the present study, its implementation involves more school counselors and specifically trained students to regulate their emotions.
The main finding of the study is that the self-regulation of emotion module is categorized as feasible to be implemented by the school counselors for reducing students' aggressive behavior. It is expected that the future study can examine the effectiveness of the self-regulation of emotion module in reducing aggressive behavior. Therefore, the effect of selfregulation of emotion module in reducing students' aggressive behavior can be empirically discovered.

\section{CONCLUSION}

Aggressive behavior becomes one of the maladaptive behaviors that often occur among students. This behavior can harm the students themselves or the people around them. The result of the preliminary study showed that aggressive behavior still become homework for educators to do, especially the school counselors, they need to prevent or even reduce it. The main finding of the study is that (a) $1 \%$ of the student's aggressive behavior was categorized as very high, $13 \%$ was categorized as high, $37 \%$ of them was categorized as medium, $43 \%$ of them was categorized as low, and $6 \%$ of them was categorized as very low; (b) hypothetical draft of selfregulation of emotion module developed from self-regulation of emotion components, namely receiving, evaluating, triggering, searching, formulating, implementing, and assessing; and (c) self-regulation of emotion module is categorized as feasible to be implemented by the school counselors for reducing students' aggressive behavior. This module consists of seven main components namely receiving, evaluating, triggering, searching, formulating, implementing, and assessing. It is suggested to conduct a study to examine the effectiveness of the module in reducing students' aggressive behavior.

\section{REFERENCES}

[1] S. Alhadi, P. Purwadi, S. Muyana, W. N. E. Saputra, and A. Supriyanto, "Agresivitas Siswa SMP di Yogyakarta," J. Fokus Konseling, vol. 4, no. 1, pp. 93-99, 2018.

[2] W. N. E. Saputra and I. B. Handaka, "Perilaku Agresi Pada Siswa SMK di Yogyakarta," J. Fokus Konseling, vol. 4, no. 1, pp. 1-8, 2018.

[3] W. N. E. Saputra, N. Hanifah, and D. N. Widagdo, "Perbedaan Tingkat Perilaku Agresi Berdasarkan Jenis Kelamin pada Siswa Sekolah Menengah Kejuruan Kota Yogyakarta," J. Kaji. Bimbing. Dan Konseling, vol. 2, no. 4, pp. 142-147, 2017.

[4] H. Hidayat, Y. Yusri, and A. Ilyas, "Profil Siswa Agresif dan Peranan Guru BK," Konselor, vol. 2, no. 2, 2013.

[5] L. Marsh, R. McGee, and S. Williams, "School climate and aggression among New Zealand high school students," N. Z. J. Psychol., vol. 43, no. 1, pp. 28-37, 2014.

[6] F. Shaikh, R. G. Viveki, and A. B. Halappanavar, "Physical and Verbal Aggressive Behaviour Pattern Among School Children in Urban Area of North Karnataka: A Cross Sectional Study.," J. Krishna Inst. Med. Sci. JKIMSU, vol. 3, no. 2, 2014.

[7] J. R. Averill, Anger and aggression: An essay on emotion. Springer Science \& Business Media, 2012.

[8] C. J. Fives, G. Kong, J. R. Fuller, and R. DiGiuseppe, "Anger, aggression, and irrational beliefs in adolescents," Cogn. Ther. Res., vol. 35, no. 3, pp. 199-208, 2011.

[9] M. Jambon, T. Colasante, J. Peplak, and T. Malti, “Anger, sympathy, and children's reactive and proactive aggression: Testing a differential correlate hypothesis," J. Abnorm. Child Psychol., vol. 47, no. 6, pp. 1013-1024, 2019. 
[10] M. Kirwan, D. J. Lanni, A. Warnke, S. M. Pickett, and M. R. Parkhill, "Emotion regulation moderates the relationship between alcohol consumption and the perpetration of sexual aggression," Violence Women, vol. 25, no. 9, pp. 1053-1073, 2019.

[11] M. D. C. Pérez-Fuentes, M. D. M. Molero Jurado, A. B. Barragán Martín, and J. J. Gázquez Linares, "Family functioning, emotional intelligence, and values: analysis of the relationship with aggressive behavior in adolescents," Int. J. Environ. Res. Public. Health, vol. 16, no. 3 , p. 478,2019

[12] E. Estévez, T. Jiménez, and L. Segura, "Emotional intelligence and empathy in aggressors and victims of school violence.," J. Educ. Psychol., vol. 111, no. 3, p. 488, 2019.

[13] D. M. Tice, R. F. Baumeister, and L. Zhang, "The role of emotion in self-regulation: Differing role of positive and negative emotions," Regul. Emot., pp. 213-226, 2004.

[14] S. J. Lepore, M. A. Greenberg, M. Bruno, and J. M. Smyth, "Expressive writing and health: Self-regulation of emotion-related experience, physiology, and behavior.," 2002.

[15] L. Siddiqah, "Pencegahan dan penanganan perilaku agresif remaja melalui pengelolaan amarah (anger management)," J. Psikol., vol. 37, no. 1, pp. 50-64, 2010.

[16] D. Hrubes, R. S. Feldman, and J. M. Tyler, "Emotion-focused deception: The role of deception in the regulation of emotion," Regul. Emot., pp. 101-126, 2004.

[17] P. Philippot and R. S. Feldman, "Cognitive regulation of emotion: Application to clinical disorders," in The regulation of emotion, Psychology Press, 2004, pp. 86-113.

[18] P. Philippot and R. S. Feldman, "Positive emotion and the regulation of interpersonal relationships," in The regulation of emotion, Psychology Press, 2004, pp. 142-171.

[19] T. F. Denson, "Angry rumination and the self-regulation of aggression," Psychol. Self-Regul. Cogn. Affect. Motiv. Process., pp. 233-248, 2009.

[20] T. F. Denson, C. N. DeWall, and E. J. Finkel, "Self-control and aggression," Curr. Dir. Psychol. Sci., vol. 21, no. 1, pp. 20-25, 2012.

[21] M. D. Gall, W. R. Borg, and J. Gall, "P.(1996)," Educ. Res. Introd. Sixth Ed. Longman Ney York, 2003.

[22] A. H. Buss and M. Perry, "The aggression questionnaire.," J. Pers. Soc. Psychol., vol. 63, no. 3, p. 452, 1992.

[23] D. J. Neal and K. B. Carey, "A follow-up psychometric analysis of the self-regulation questionnaire.," Psychol. Addict. Behav., vol. 19, no. 4, p. 414, 2005.

[24] L. Chang, D. Schwartz, K. A. Dodge, and C. McBride-Chang, "Harsh parenting in relation to child emotion regulation and aggression.," $J$. Fam. Psychol., vol. 17, no. 4, p. 598, 2003.
[25] S. R. Ramsden and J. A. Hubbard, "Family expressiveness and parental emotion coaching: Their role in children's emotion regulation and aggression," J. Abnorm. Child Psychol., vol. 30, no. 6, pp. 657-667, 2002.

[26] E. M. Forman, J. D. Herbert, E. Moitra, P. D. Yeomans, and P. A. Geller, "A randomized controlled effectiveness trial of acceptance and commitment therapy and cognitive therapy for anxiety and depression," Behav. Modif., vol. 31, no. 6, pp. 772-799, 2007.

[27] C. Garofalo, C. J. Holden, V. Zeigler-Hill, and P. Velotti, "Understanding the connection between self-esteem and aggression: The mediating role of emotion dysregulation," Aggress. Behav., vol. 42, no. 1, pp. 3-15, 2016.

[28] T. Roberton, M. Daffern, and R. S. Bucks, "Maladaptive emotion regulation and aggression in adult offenders," Psychol. Crime Law, vol. 20, no. 10, pp. 933-954, 2014.

[29] C. N. DeWall, E. J. Finkel, and T. F. Denson, "Self-control inhibits aggression," Soc. Personal. Psychol. Compass, vol. 5, no. 7, pp. 458472, 2011.

[30] L. Berkowitz, "A different view of anger: The cognitive-neoassociation conception of the relation of anger to aggression," Aggress. Behav., vol. 38, no. 4, pp. 322-333, 2012.

[31] R. Hortensius, D. J. Schutter, and E. Harmon-Jones, "When anger leads to aggression: Induction of relative left frontal cortical activity with transcranial direct current stimulation increases the anger-aggression relationship," Soc. Cogn. Affect. Neurosci., vol. 7, no. 3, pp. 342-347, 2011.

[32] M. Mikulincer and P. R. Shaver, "Attachment, anger, and aggression," Hum. Aggress. Violence Causes Manif. Consequences, pp. 241-257, 2011

[33] B. M. Wilkowski, M. D. Robinson, and W. Troop-Gordon, "How does cognitive control reduce anger and aggression? The role of conflict monitoring and forgiveness processes.," J. Pers. Soc. Psychol., vol. 98, no. 5 , p. $830,2010$.

[34] R. H. Hornsveld, H. L. Nijman, C. R. Hollin, and F. W. Kraaimaat, "Aggression control therapy for violent forensic psychiatric patients: Method and clinical practice," Int. J. Offender Ther. Comp. Criminol., vol. 52, no. 2, pp. 222-233, 2008.

[35] I. Burt, S. H. Patel, and S. V. Lewis, "Anger management leadership groups: A creative intervention for increasing relational and social competencies with aggressive youth," J. Creat. Ment. Health, vol. 7, no. 3, pp. 249-261, 2012.

[36] P. Orpinas, A. M. Horne, and M. V. P. Project, "A teacher-focused approach to prevent and reduce students' aggressive behavior: The GREAT Teacher Program," Am. J. Prev. Med., vol. 26, no. 1, pp. 2938,2004 